\title{
Incident Monitoring of Glyphosate and Aminomethylphosphonic Acid in Natural Waters - Experimental Set-up and Validation
}

\author{
Britta Jahnke ${ }^{1, ~ *}$, Bernd Niemeyer ${ }^{1,2}$ \\ ${ }^{1}$ Institute of Coastal Research / Molecular Recognition and Separation, Helmholtz-Zentrum Geesthacht, Geesthacht, Germany \\ ${ }^{2}$ Institute of Thermodynamics, Helmut-Schmidt-University / University of the Federal Armed Forces Hamburg, Hamburg, Germany
}

Email address:

Britta.Jahnke@hzg.de (B. Jahnke), Bernd.Niemeyer@hsu-hh.de (B. Niemeyer)

*Corresponding author

\section{To cite this article:}

Britta Jahnke, Bernd Niemeyer. Incident Monitoring of Glyphosate and Aminomethylphosphonic Acid in Natural Waters - Experimental Setup and Validation. International Journal of Environmental Monitoring and Analysis. Vol. 4, No. 3, 2016, pp. 75-81.

doi: 10.11648/j.ijema.20160403.12

Received: February 27, 2016; Accepted: March 8, 2016; Published: April 20, 2016

\begin{abstract}
A measuring system based on sequential injection analysis (SIA) for the detection of the herbicide glyphosate and its main metabolite aminomethylphosphonic acid (AMPA) in natural waters is presented. The system is automated to enable an unattended monitoring of the analytes. Due to its compact manifold it can easily be integrated into existing observing systems or could be used on board of research vessels. Here we show the experimental setup and the results of the system's performance during experimental periods of 20 hours in the laboratory as well as in an observing station situated at the Elbe river in Hamburg, Germany. An incident with elevated glyphosate and AMPA concentrations was simulated by injecting spiked river water samples. The results show a good stability of the system over the experimental period.
\end{abstract}

Keywords: Glyphosate, Roundup, AMPA, Sequential Injection Analysis, SIA, Phosphororganic Analysis

\section{Introduction}

The target compound in this study is glyphosate, the active ingredient of one of the most widely applied herbicides. It was introduced as "Roundup" by Monsanto in the 1970s. 718,600 tons of glyphosate containing pesticides were employed worldwide in 2012 [1] and a continuing increase is to be expected. The herbicides are extensively used to control weeds in agriculture but also in urban areas and railway properties [2]. Glyphosate and its main metabolite aminomethylphosphonic acid (AMPA) are frequently detected in ground and surface waters despite their good adsorption properties in soil. Especially after rainfall events shortly after application glyphosate and AMPA leach into the water phase [3]. An evaluation of measurements in European surface waters between 1993 and 2009 summarized findings of glyphosate in almost one third of the samples. AMPA was even detected in half of the samples [4]. A study investigated the runoff of glyphosate and AMPA from an urban Area in
Belgium. Maximum concentrations of 6.1 , and $5.8 \mu \mathrm{g} \mathrm{L}^{-1}$, respectively, were reported [5]. Glyphosate is frequently found in groundwater in agricultural areas in Denmark with maximum values of $31 \mu \mathrm{g} \mathrm{L}^{-1}$ [6]. In the Spanish river Llobregat glyphosate concentrations between 20 and $60 \mu \mathrm{g} \mathrm{L}^{-1}$ were found. Three days after application a maximum of 139 $\mu \mathrm{g} \mathrm{L}^{-1}$ was reached [7].

In general glyphosate is marketed as relatively nontoxic, because its mode of action is assumed to exclusively target plant organisms [8]. However, lately there have been increasing concerns about its impact on the environment due to the large quantities applied. In May 2015 the IARC (International Agency for Research on Cancer) classified glyphosate as probably carcinogenic to humans [9]. Glyphosate is currently re-evaluated as its approval at the European level expires in June 2016 [10].

Analyses of pesticides in surface waters show that the concentrations are highly dynamic and largely influenced by point sources. The few continuous measurements resulted in high hourly fluctuations [11]. A monitoring of glyphosate 
could give important information about the extent of its application or events that lead to an increased leaching into the water phase.

Monitoring of contaminants captures temporal events or spatial variations of concentration and thus is an important tool for the assessment of ecosystem condition. Based on this knowledge, particular problems can be addressed and the status of the ecosystem can be improved [12].

Sampling with subsequent analysis at a laboratory is most commonly used, but a trend towards on-site analyses can be observed. The motivation is a higher spatial and temporal resolution of measurement data and the avoidance of typical challenges concerning sampling and transportation of samples to the laboratory, e.g. the risk of contamination or transformation of the analyte of interest between sampling and analysis [13]. Furthermore, incident reaction times can be significantly reduced if the data are constantly reevaluated by e.g. a software.

Existing measuring systems are operated on board of research vessels or integrated in observing systems. Established observing systems operated by research institutes or public authorities offer an infrastructure with power and a central sampling device. Time and effort of analyses are drastically reduced.

In this study an automated measuring system for the detection of glyphosate and its main metabolite AMPA (aminomethylphosphonic acid) in environmental waters is developed. Its principle is based on sequential injection analysis (SIA). The method emanated from flow injection analysis (FIA) and was introduced by Ruzicka and Marshall in 1990 [14].

SIA allows the automation of wet chemical analyses. Various components, e.g. detectors or reactors can easily be integrated into the manifold and several parameters can be adapted by simply modifying the software [15]. Its plain structure and versatility make SIA suitable for use in a compact and mobile measuring system [14]. The method has good green chemical credentials with only small amounts of reagents used. Its portability makes it very suitable for on-site analysis [12].

The working principle is based on the computer-controlled interaction of a syringe pump and a rotary selection valve (Figure 1). The components are connected via flexible tubes (generally made of Teflon).

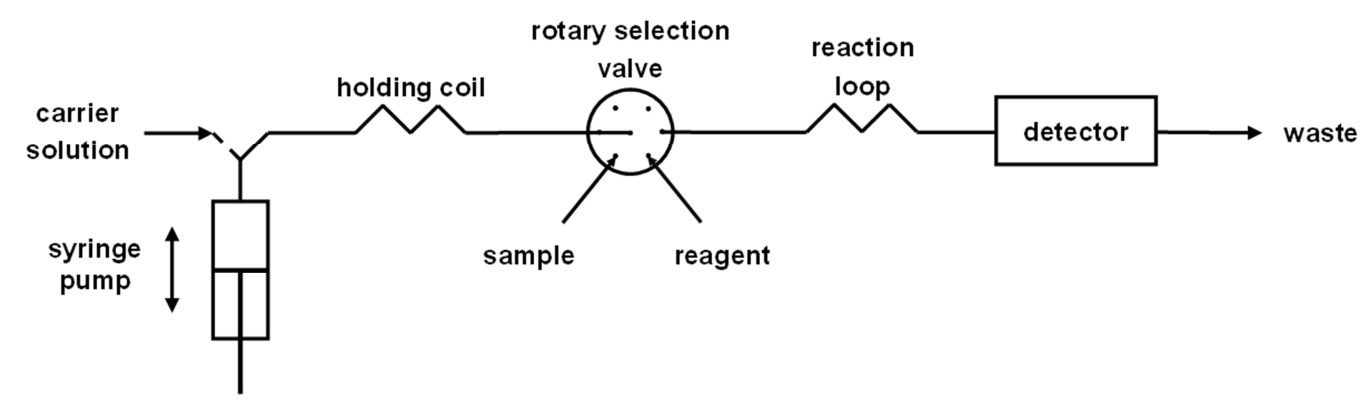

Figure 1. Scheme of sequential injection analysis (SIA).

The central port of the rotary selection valve is alternately switched to the other ports so that sample and reagents are drawn into the system and the reaction product generates a detectable measuring signal.

Associated with water monitoring FIA and SIA methods are mainly applied for the observing of industrial sewage discharges and leachates from agriculture and landfills, for nutrient budget studies and for the data acquisition for environmental databases. Since the early 1980s FIA and later SIA systems are often deployed on board of research vessels [16]. Existing systems applied in the freshwater environment mainly concentrate on nutrients (e.g. phosphate, ammonium, nitrate), (heavy) metals (e.g. mercury, cadmium, lead, copper, iron, chromium) or different ions (e.g. chloride, fluoride) [17].

Only a few measuring systems for the monitoring of organic compounds have been described so far. $\mathrm{Xu}$ et al. presented a FIA method for the determination of $p$ aminophenol in industrial waste water with a detection limit of $19 \mu \mathrm{g} / \mathrm{L}$ [18]. Cetylpyridiniumchloride, a cationic tenside, was also detected by a FIA system in pond water, waste water, sediment and soil. In this system, an LOD (limit of detection) of $110 \mu \mathrm{g} / \mathrm{L}$ was reached [19]. Mulchandani et al. developed a FIA method for the analysis of organophosphorus pesticides. The amperometric biosensor detected paraoxon and methyl parathion in distilled water and simulated well water with LODs of 5,5 and 5,3 $\mu \mathrm{g} / \mathrm{L}$, respectively [20]. A flow injection method for the determination of dissolved organic carbon (DOC) in estuarine and coastal waters with an LOD of $800 \mu \mathrm{g} / \mathrm{L}$ was developed by Koshy et al [21].

The analysis of glyphosate and AMPA in this work is based on the o-phthaldialdehyde (OPA) derivatization of primary amines in presence of a thiol as a nucleophile to form a fluorescent product (Figure 2).

AMPA as a primary amine is directly derivatized. Glyphosate is a secondary amine and needs to be oxidized with calciumhypochlorite $\left(\mathrm{Ca}(\mathrm{OCl})_{2}\right)$ to glycine before the derivatization reaction. This detection principle is generally realized as an HPLC method with post-column derivatization $[22,23]$. Its implementation in a SIA system [24, 25] or as a sequential-injection reversed-phase chromatography method [26] is also described. The OPA derivatization of glyphosate and AMPA is very sensitive and the detection is realized using an optical detector, which allows its implementation in a SIA system. 


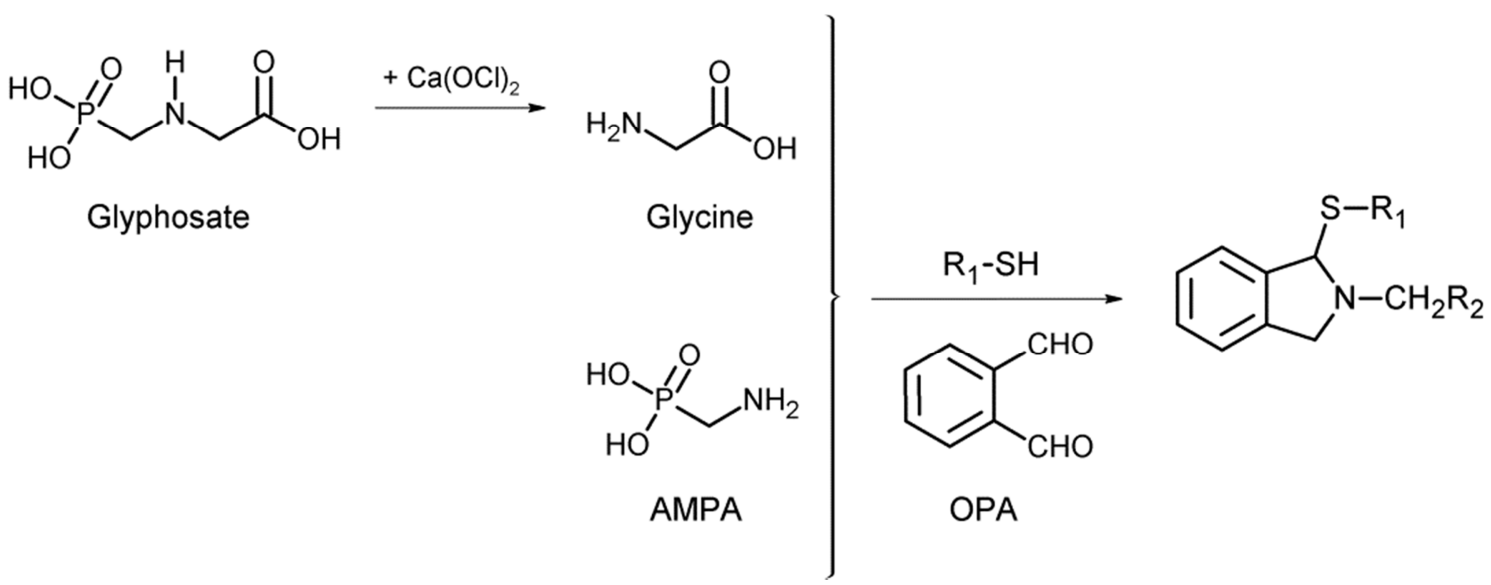

Figure 2. Derivatization reaction: Glyphosate is oxidized by calciumhypochlorite to glycine which reacts with OPA in the presence of a thiol to form a fluorescent isoindole derivative. AMPA is directly derivatized by OPA with a thiol.

The proposed method is considered to be a potential incident monitoring tool for the detection of glyphosate and AMPA in areas where leaching of the contaminants into the water phase is likely to occur.

\section{Experimental}

\subsection{Chemicals and Reagents}

All chemicals were of analytical grade and purchased from Sigma-Aldrich (Seelze, Germany) or Merck (Darmstadt, Germany) unless stated otherwise. All reagents were prepared with purified water obtained from a Milli-Q system (Millipore, Schwalbach, Germany) and were filtered (0.2 $\mu \mathrm{m})$ and degassed. The carrier solution was $0.005 \mathrm{M}$ $\mathrm{KH}_{2} \mathrm{PO}_{4}$. The $\mathrm{pH}$ value of the mobile phase utilized for chromatographic separation was adjusted to 2.0 with $\mathrm{H}_{3} \mathrm{PO}_{4}$. A stock solution of $\mathrm{Ca}(\mathrm{OCl})_{2}$ (for synthesis) with a concentration of $2.3 \mathrm{~g} \mathrm{~L}^{-1}$ was prepared. The stock solution was stored at $-20^{\circ} \mathrm{C}$. The phosphate buffer of the $\mathrm{Ca}(\mathrm{OCl})_{2}$ working solution was prepared by dissolving $17.4 \mathrm{~g}$ of $\mathrm{K}_{2} \mathrm{HPO}_{4}$ and $0.5 \mathrm{~g}$ of $\mathrm{NaCl}$ in $50 \mathrm{~mL}$ purified water. The $\mathrm{pH}$ was adjusted to 11.0 with $\mathrm{NaOH}(30 \%) .11 .25 \mathrm{~mL}$ of this buffer and $13.75 \mathrm{~mL}$ purified water were mixed and $164 \mu \mathrm{L}$ of the $\mathrm{Ca}(\mathrm{OCl})_{2}$ stock solution was added in order to obtain a final $\mathrm{Ca}(\mathrm{OCl})_{2}$ concentration of $15 \mathrm{mg} \mathrm{L}^{-1}$. For the OPA reagent a borate buffer solution was prepared by dissolving $10.25 \mathrm{~g}$ of $\mathrm{Na}_{2} \mathrm{CO}_{3}, 3.25 \mathrm{~g}$ of $\mathrm{H}_{3} \mathrm{BO}_{3}$ and $4.75 \mathrm{~g}$ of $\mathrm{K}_{2} \mathrm{SO}_{4}$ in ca. $240 \mathrm{~mL}$ purified water. The $\mathrm{pH}$ was adjusted to 10.0 with $\mathrm{NaOH}(30 \%) .400 \mathrm{mg}$ of o-phthaldialdehyde and $500 \mathrm{mg}$ of $\mathrm{N}$-acetyl-L-cysteine was dissolved in $7 \mathrm{~mL}$ ethanol and added to the borate buffer. $1.0 \mathrm{~mL}$ Brij 35 solution (10\%) was added and the volume was adjusted with purified water to $250 \mathrm{~mL}$. This solution was stored at room temperature in a dark glass bottle. Water samples were collected from the Elbe river in Hamburg, Germany. The samples were filtered through $0.45 \mu \mathrm{m}$ mixed cellulose ester membranes and stored in glass bottles. Filtered river water was spiked by adding 50 $\mu \mathrm{g} \mathrm{L^{-1 }}$ (laboratory study), or $300 \mu \mathrm{g} \mathrm{L}^{-1}$ (field study) glyphosate and AMPA. The standard solution contained glyphosate and AMPA in mobile phase ( $\mathrm{pH} 2.0)$ with a concentration of $50 \mu \mathrm{g} \mathrm{L}^{-1}$ (laboratory study) or $500 \mu \mathrm{g} \mathrm{L}^{-1}$ (field study) each.

\subsection{Instrumentation}

The experimental setup is depicted in Figure 2. An HPLC-pump (Knauer Smartline 100, Berlin, Germany) is connected to an ion exchange column (Hamilton PRP$\mathrm{X} 400$, Reno, NV, USA) via a 6-ports/3-channel injection valve (Knauer A1370). This setup is coupled via a T-piece to a 7-port/1-channel valve (Knauer A1374) which is connected via a holding coil (PTFE tubing, $0.8 \mathrm{~mm}$ i.d.) to a $2.5 \mathrm{~mL}$ syringe pump (Hamilton PSD/4). A heated reactor $\left(45^{\circ} \mathrm{C}\right)$ containing $1 \mathrm{~m}$ woven PTFE tubing $(0.8 \mathrm{~mm}$ i.d. $)$ in a heating block is used as reaction coil (Global FIA, Fox Island, WA, USA). All other connections are made of PTFE tubing $(0.5 \mathrm{~mm}$ i.d.). The syringe pump and the valve are connected via USB to a personal computer and are controlled by scripts written in the python programming language according to Frank [27, 28]. An Agilent fluorescence detector (1200 Series, Boeblingen, Germany) with an $8 \mu \mathrm{L}$ flow cell is employed in the laboratory setup (ex. $230 \mathrm{~nm}$, em. $445 \mathrm{~nm}$ ). For the field study this detector is replaced by a compact modular detector: A high power LED (ex. 365 nm, Prizmatix Mic-LED-365, Givat Shmuel, Israel) is coupled to a cuvette holder with a fluorescence cuvette (100 $\mu \mathrm{L}$, Hellma Analytics, Müllheim, Deutschland). The cuvette holder is connected to a photomultiplier (Counting Unit C8855-01, Hamamatsu Photonics, Hamamatsu, Japan) via an optical fiber (core diameter $1.5 \mathrm{~mm}$ ) with subsequent collimating lens (Avantes, Apeldoorn, the Netherlands) and bandpass filter $(460 \mathrm{~nm})$. The photomultiplier is connected via USB to the personal computer and is also controlled by scripts written in the python programming language.

The setup of the SIA system is shown in Figure 3. The derivatization and analysis of glyphosate and AMPA is carried out according to our recently published method [24]. To allow for a continuous measurement, the setup is com- 
pleted by a peristaltic pump and a glyphosate standard (500 $\mu \mathrm{g} \mathrm{L}^{-1}$ in mobile phase, $\mathrm{pH}$ 2.0). The peristaltic pump provides for a constant flow of filtered river water through the sample loop of the injection valve. The glyphosate standard is directly connected to the rotary selection valve.

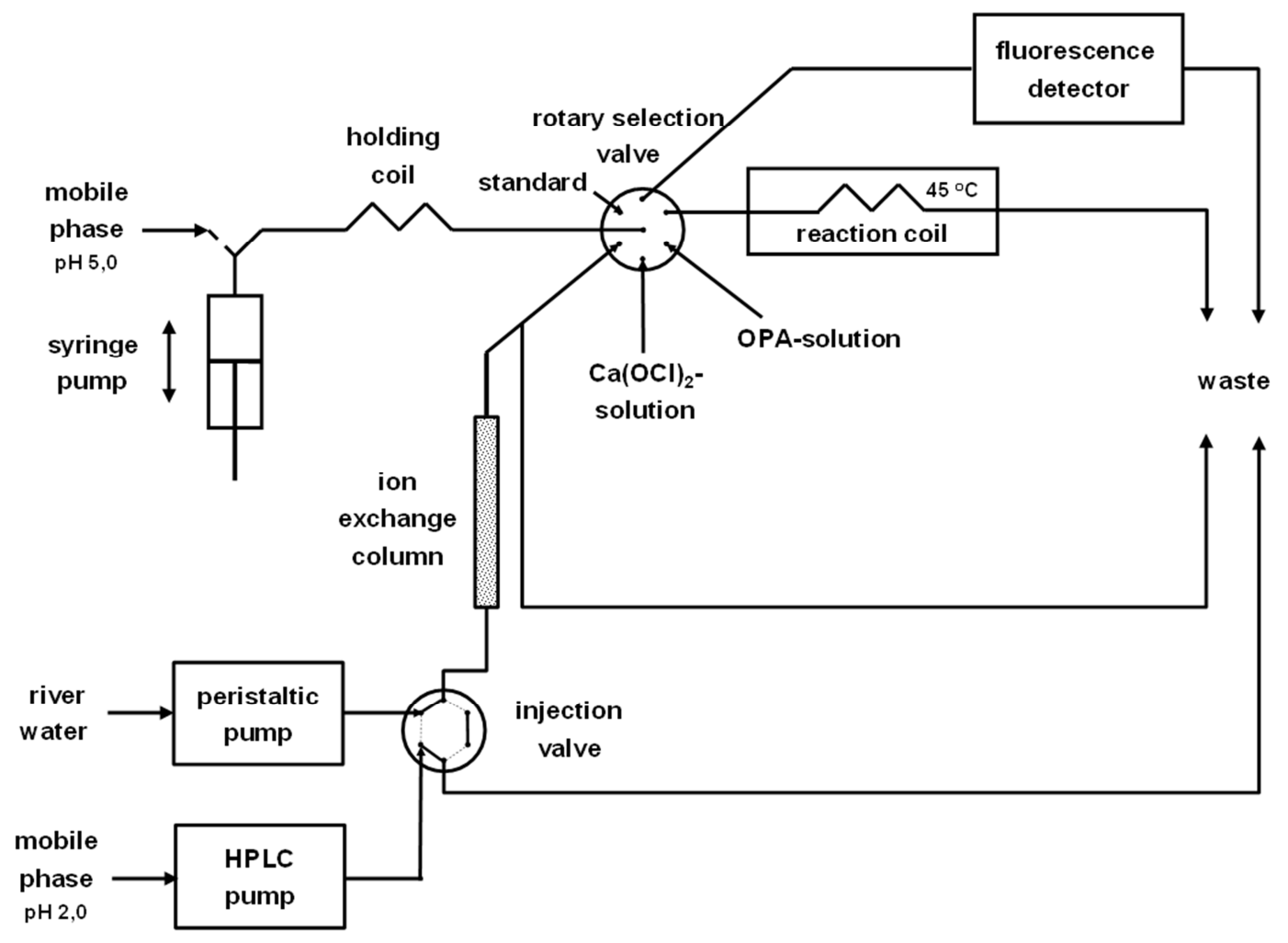

Figure 3. Scheme of the SIA system utilized for the detection of glyphosate and AMPA.

For the field study the SIA system was integrated into the observing station Seemannshöft, operated by the Hamburg Institute for Hygiene and Environment and situated at the Elbe river in Hamburg, Germany.

Each measurement cycle consists of four analyses in succession. At first the standard is analyzed by the AMPAprogram (addition of OPA-solution) in order to account for a potential drift of the detector's base line. Subsequently the same standard is analyzed by the glyphosate-program (successive addition of $\mathrm{Ca}(\mathrm{OCl})_{2}-$ and OPA-solution) to confirm the stability of the calciumhypochlorite solution. Afterwards the injection valve is switched to inject river water into the system and the sample is analyzed by the AMPA program. After completion of the AMPA program, another sample is taken by the injection valve and the glyphosate program starts. The sequence of four measurements is started automatically every 30 minutes over a time range of 20 hours.

In order to simulate an incident, spiked river water is manually introduced into the sample loop of the injection valve with the peristaltic pump temporarily separated from the valve.

\section{Results and Discussion}

\subsection{Laboratory Conditions}

Over a period of 20 hours the base line (Standard 0) did not notably fluctuate with a standard deviation of only $1.6 \%$ (Figure 4). Also the measurement of the glyphosate standard (Standard 50) showed a standard deviation of only $1.2 \%$. Thus both trends proved a very good stability of the system over the experimental period. No loss of activity of both OPA- as well as $\mathrm{Ca}(\mathrm{OCl})_{2}$-solutions could be observed.

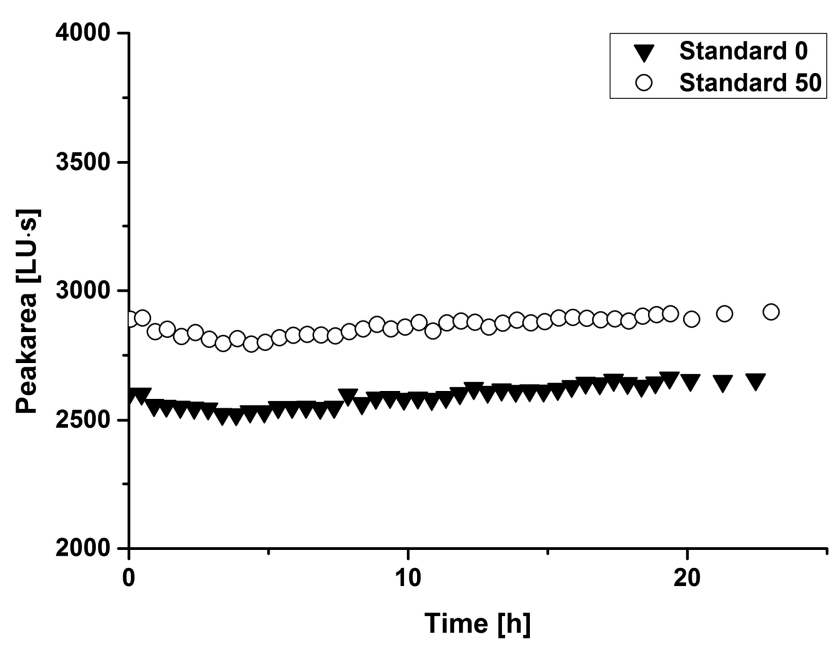

Figure 4. Analysis of standards over a time range of 20 hours (LU: luminescence units).

The analysis of the standard was integrated in order to act as an additional parameter for the system's stability. In case 
of a baseline drift or a deterioration of reagents measured values could be converted based on the results of the standards. According to the data demonstrated, the frequency of the standard's analysis could be reduced in order to further minimize reagent consumption and to decrease the duration of an individual measurement.

Leaking incidents were simulated by introducing spiked glyphosate and AMPA samples into the sample loop of the injection valve. The results of the elevated glyphosate and AMPA concentrations in comparison to samples without the addition of both analytes are depicted in Figure 5.

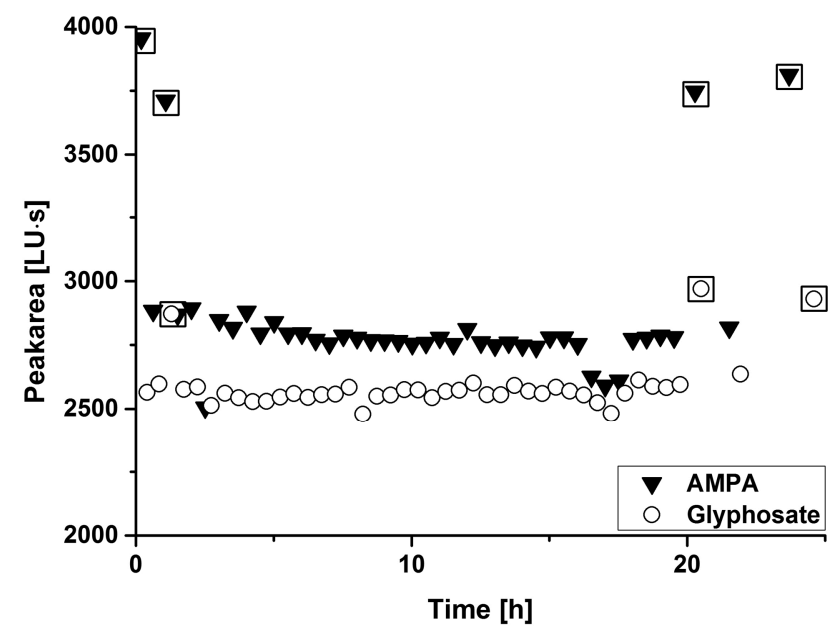

Figure 5. Results of the laboratory on-line measurement of glyphosate and AMPA (labelled: spiked samples, $50 \mu \mathrm{g} / \mathrm{L}$ ).

Again the results of the on-line measurement of glyphosate and AMPA reflected a good stability of the system over a period of 20 hours with standard deviations of less than $\pm 3.5 \%$. The results are in good agreement with the system's typical sensitivity evaluated from the slopes of the calibration curves of $20.8(\mathrm{LU} \cdot \mathrm{s}) /\left(\mu \mathrm{g} \cdot \mathrm{L}^{-1}\right)$ and $7.3(\mathrm{LU} \cdot \mathrm{s}) /\left(\mu \mathrm{g} \cdot \mathrm{L}^{-1}\right)$ for AMPA and glyphosate, respectively. The limits of detection are $16 \mu \mathrm{g} / \mathrm{L}$ (glyphosate) and $9 \mu \mathrm{g} / \mathrm{L}$ (AMPA) [24].

\subsection{Field Study}

Within the observation station the SIA system could be easily connected to an available ultrasonic filter from which the peristaltic pump continuously drew filtered river water into the sample loop of the injection valve. After a few measurements the filtered river water blocked the column which was traced back to the filter's pore size of $2.0 \mu \mathrm{m}$. Afterwards a river water sample was filtered $(0.45 \mu \mathrm{m})$ and stored in a glass bottle from where the peristaltic pump drew the water for the time of the further experiment.

Figures 6 and 7 show the respective results from the above described setup under field conditions. The results of the field study were comparable to those obtained in the laboratory. The standard deviations of the repeated measurements of the standard of 3.7\% (standard 0) and 3.9\% (standard 500) again show a good reliability of the SIA system even integrated into an observing station.

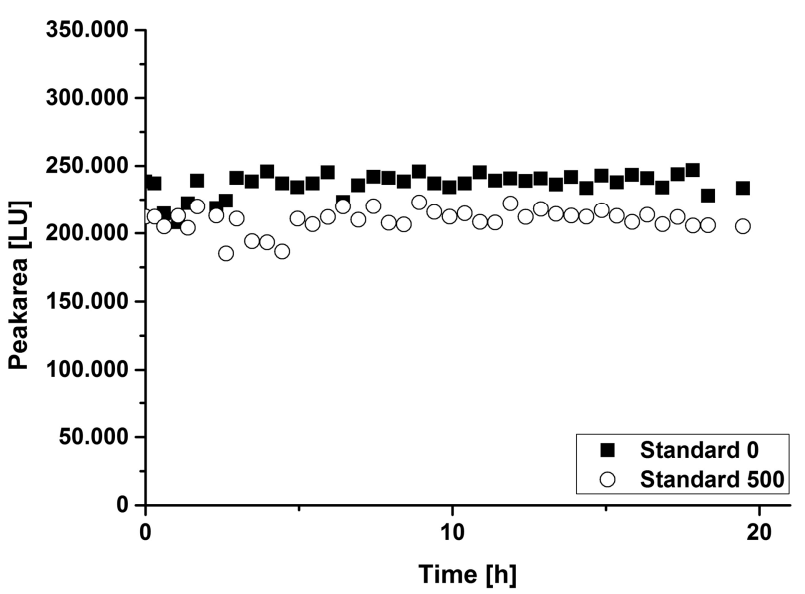

Figure 6. Analysis of standards over a time range of 20 hours during the field study.

Actual concentrations of glyphosate and AMPA in the Elbe river are well below the detection limits of the proposed method. However the results of the spiked water samples show that the detection of elevated glyphosate and AMPA concentrations in case of a leaking incident would be possible. The spiked water samples show higher fluorescence signals (labelled values in Figure 7) than river water without the addition of the analytes. In order to detect both analytes in environmentally relevant concentrations a preconcentration would be necessary.

Due to the setup with a constant flow of filtered river water through the sample loop of the injection valve an on-line measurement of glyphosate and AMPA could easily be implemented. The compact size of the system made the temporary integration into an existing observing station feasible.

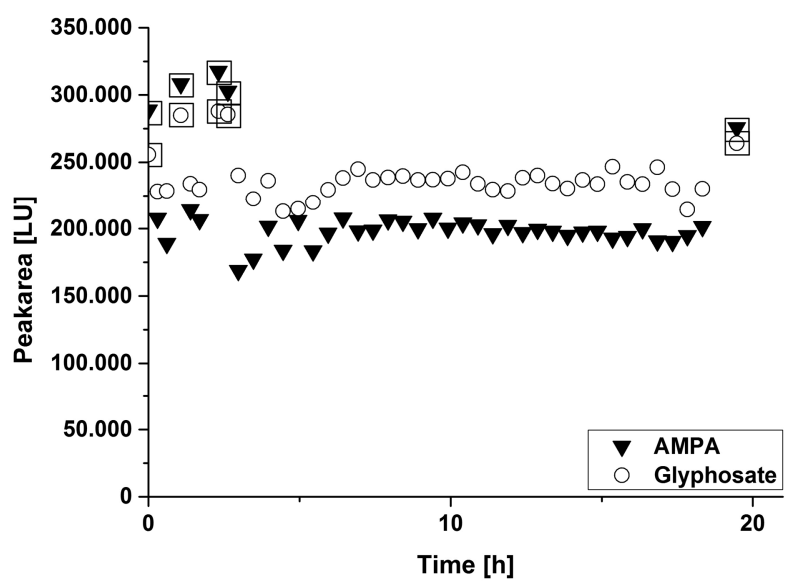

Figure 7. Results of the on-line measurement of glyphosate and AMPA (labelled: spiked samples, $300 \mu \mathrm{g} / \mathrm{L}$ ) during the field study.

Still the values of the spiked samples taken at the end of the measurement period were lower than those at the beginning of the experiment. This effect could also be observed in preceding experiments in the laboratory, where an occasional manual injection of $\mathrm{KOH}(0.1 \mathrm{M})$ in order to regenerate the column resulted in an amelioration. 


\section{Conclusion}

The presented SIA system was evaluated with regard to its applicability as an incident monitoring tool for the detection of glyphosate and AMPA in natural waters. The method was successfully tested over a time range of 20 hours. A potential leaking incident of glyphosate and AMPA was simulated by injecting spiked river water samples. The measurement was fully automated and stable during this period.

We showed that this system is applicable for the detection of higher glyphosate and AMPA concentrations in case of a leaking incident. In order to detect lower analyte concentrations a preconcentration of water samples would be necessary. The compact fluorescence detector needs to be optimized for further field studies in order to reach better detection limits. The integration of another syringe pump for the dosing of $\mathrm{KOH}$ would be necessary for prolonged experimental periods.

The compact manifold could easily be integrated into an existing observing station. Water continuously flows through the injection valve, which makes the implementation of an on-line measurement very facile. In case of a sufficient system pressure the SIA system could be linked to an existing filter without the peristaltic pump, resulting in an even smaller manifold.

\section{Acknowledgements}

We would like to thank the Hamburg Institute for Hygiene and Environment for the possibility to test our system in their observing station Seemannshöft, Hamburg, Germany.

\section{References}

[1] Glyphosate herbicide sales boom powers global biotech industry. Sustainable pulse. 21. 08. 2014. http://sustainablepulse.com/2014/08/21/glyphosate-salesboom-powers-global-biotech-industry/\#.VYABjmOBiSr (accessed 16.06.2015).

[2] Deutscher Bundestag. Drucksache 16/13993. Einsatz von Pestiziden auf Strecken der deutschen Bahn. 07. 09. 2009.

[3] S. Daouk, L. F. de Alencastro, H. R. Pfeifer. The herbicide glyphosate and its metabolite AMPA in the Lavaux vineyard area, western Switzerland: Proof of widespread export to surface waters. Part II: The role of infiltration and surface runoff. J Environ Sci Heal B. vol. 48, pp. 725-736, 2013.

[4] H. Horth. Monitoring results for surface water and groundwater. European glyphosate environmental information source. 2010.

[5] T. Tang, W. Boenne, N. Desmet, P. Seuntjens, J. Bronders, A. van Griensven. Quantification and characterization of glyphosate use and loss in a residential area. Sci Total Environ. vol. 517, pp. 207-214, 2015.

[6] A. E. Rosenbom, P. Olsen, F. Plauborg, R. Grant, R. K. Juhler, W. Brusch, J. Kjaer. Pesticide leaching through sandy and loamy fields - long-term lessons learnt from the Danish pesticide leaching assessment programme. Environ Pollut. vol. 201, pp. 75-90, 2015.
[7] L. Puertolas, J. Damasio, C. Barata, A. M. V. M. Soares, N. Prat. Evaluation of side-effects of glyphosate mediated control of giant reed (Arundo donax) on the structure and function of a nearby Mediterranean river ecosystem. Environ Res. vol. 110, pp. 556-564, 2010.

[8] K. R. Solomon, D. G. Thompson. Ecological risk assessment for aquatic organisms from over-water uses of glyphosate. J Toxicol Env Heal B. vol. 6, pp. 289-324, 2003.

[9] K. Z. Guyton, D. Loomis, Y. Grosse, F. El Ghissassi, L. Benbrahim-Tallaa, N. Guha, C. Scoccianti, H. Mattock, K. Straif. Carcinogenicity of tetrachlorvinphos, parathion, malathion, diazinon, and glyphosate. Lancet Oncol. vol. 16, pp. 490-491, 2015.

[10] Fragen und Antworten zu Glyphosat. Bundesministerium für Ernährung und Landwirtschaft. http://www.bmel.de/DE/Landwirtschaft/Pflanzenbau/Pflanzen schutz/_Texte/GlyphosatFAQ.html (accessed 28. 12. 2015).

[11] K. M. A. Holvoet, P. Seuntjens, P. A. Vanrolleghem. Monitoring and modeling pesticide fate in surface waters at the catchment scale. Ecol Model. vol. 209, pp. 53-64, 2007.

[12] I. D. McKelvie, S. D. Kolev, P. J. Worsfold. More with less: Advances in flow and paper-based monitoring of nutrients in aquatic systems. Pure Appl Chem. vol. 84, pp. 1973-1982, 2012.

[13] D. T. E. Hunt, A. L. Wilson. The chemical analysis of water. 2nd ed. Oxford: The Alden Press, 1986, pp. 92 ff.

[14] J. Ruzicka, G. D. Marshall. Sequential injection - a new concept for chemical sensors, process analysis and laboratory assays. Anal Chim Acta. vol. 237, pp. 329-343, 1990.

[15] N. Dantan. Fließinjektionsanalyse und sequentielle Injektionsanalyse für Prozessmonitoringaufgaben Einsatzmöglichkeiten in der pharmazeutischen Industrie. Dissertation, Humboldt-Universität zu Berlin, Berlin, Germany, 2002.

[16] K. N. Andrew, N. J. Blundell, D. Price, P. J. Worsfold. Flowinjection techniques for water monitoring. Anal Chem. vol. 66, pp. 916 A-922 A, 1994.

[17] C. E. Lenehan, N. W. Barnett, S. W. Lewis. Sequential injection analysis. Analyst. vol. 127, pp. 997-1020, 2002.

[18] H. Xu, C. F. Duan, Z. F. Zhang, J. Y. Chen, C. Z. Lai, M. Lian, L. J. Liu, H. Cui. Flow injection determination of paminophenol at trace level using inhibited luminoldimethylsulfoxide- $\mathrm{NaOH}$-EDTA chemiluminescence. Water Res. vol. 39, pp. 396-402, 2005.

[19] K. Agrawal, G. Agnihotri, K. Shrivas, G. L. Mundhara, K. S. Patel, P. Hoffmann. Determination of cationic surfactants in environmental samples by flow injection analysis. Microchim Acta. vol. 147, pp. 273-278, 2004.

[20] P. Mulchandani, W. Chen, A. Mulchandani. Flow injection amperometric enzyme biosensor for direct determination of organophosphate nerve agents. Environ Sci Technol. vol. 35, pp. 2562-2565, 2001.

[21] K. Koshy, M. Mataki. Photochemical oxidation and flow injection conductivity determination of dissolved organic carbon in estuarine and coastal waters. Lab Robotics Automat. vol. 12, pp. 157-163, 2000. 
[22] DIN 38407-22:2001-10 - Gemeinsam erfassbare Stoffgruppen (Gruppe F) Teil 22: Bestimmung von Glyphosat und Aminomethylphosphonsäure (AMPA) in Wasser durch Hochleistungs-Flüssigkeitschromatographie (HPLC). Deutsches Institut für Normung e. V.: Berlin, Germany, 2001.

[23] Method 547 - Determination of glyphosate in drinking water by direct-aqueous-injection HPLC, post-column derivatization, and fluorescence detection. U.S. Environmental Protection Agency: Cincinnati, OH, USA, 1990.

[24] B. Jahnke, C. Frank, J. F. Fernández, B. Niemeyer. A sequential injection analysis method for the determination of glyphosate and aminomethylphosphonic acid in water samples. Am Chem Sci J. vol. 5, pp. 163-173, 2015.

[25] S. D. Colombo, J. C. Masini. Developing a fluorimetric sequential injection methodology to study adsorption/desorption of glyphosate on soil and sediment samples. Microchem J. vol. 98, pp. 260-266, 2011.
[26] S. D. Colombo, J. C. Masini. A sequential-injection reversedphase chromatography method for fluorimetric determination of glyphosate and aminomethylphosphonic acid. Anal Methods-UK. vol. 6, pp. 490-496, 2014.

[27] C. Frank, F. Schroeder. Using sequential injection analysis to improve system and data reliability of online methods: Determination of ammonium and phosphate in coastal waters. J Autom Method Manag. vol. 2007, pp. 1-6, 2007.

[28] C. Frank, F. Schroeder, R. Ebinghaus, W. Ruck. A fast sequential injection analysis system for the simultaneous determination of ammonia and phosphate. Microchim Acta. vol. 154, pp. 31-38, 2006. 